\title{
Flow Characteristics through Saturated Soil: Experimental Study
}

\author{
SUDIP BASACK $^{1 *}$, GHRITARTHA GOSWAMI ${ }^{2}$, PRANDEEP DEKA $^{3}$ \\ MRINAL KR BARMAN ${ }^{4}$, KIVIPU CHISHI $^{5}$ \\ 1. Elitte College of Engineering, Sodepur, Kolkata, INDIA \\ 2. Scholar's Institute of Technology and Management, Guwahati, Assam, INDIA \\ 3. Extramarks Education Private Limited, Guwahati, Assam, INDIA \\ 4. Neccon Power and Infra Limited, Assam, INDIA \\ 5. Civil Engineering, Kaziranga University, Jorhat, Assam, INDIA
}

\begin{abstract}
The flow characteristics through saturated soil is complex. For low heads, the flow is essentially linear, where Darcy's law is applicable. For higher head, the flow is nonlinear and mathematically identified as Forchheimer's flow. The critical flow velocity for this transition and the relevant Reynold's number depends upon several factors, including soil and fluid characteristics. In this paper, an experimental investigation has been carried out by means of falling head permeameter with locally available soft soil sample. A critical analysis and interpretations of the test results to identify the linear and nonlinear flow characteristics have been performed and important conclusions are drawn therefrom.
\end{abstract}

Key-Words: - Darcy's law, Falling head permeameter, Forchheimer flow, Saturated Soil

Received: September 20, 2019. Revised: February 9, 2020. Accepted: March 2, 2020. Published: March 12, 2020.

\section{Introduction}

Water is essential for humanity and among one of the most core concerns in the present civilization. For growth and sustainability of a country, the optimum usage of water resources is of utmost importance, from the viewpoint of its domestic, agricultural and industrial usages. The fresh groundwater forms the major part of sustainable water resources [1]. Hence, ground water recharge, inter basin water transfer, re-use of water, etc., are the various aspects for adequate water resource planning and management [2].

The hydrological processes concerning the forecasting and control of groundwater requires adequate understanding of the flow characteristics through the subsoil. The majority of soil in India consists of soft clay in form of alluvial soil and marine soil [3]. Thus, the groundwater flow pattern is mostly influenced by horizontal and vertical hydraulic conductivity of soft clay, apart from other essential parameters [4].

Wang et al. [5] carried out experimental investigations through natural porous medium at low Reynold's number under different hydraulic heads. Experimental investigation on nonlinear groundwater flow was done by Zhang et al [6] and Tan et al [7]. Numerical modelling to assess the flow of water through porous medium under linear and non-linear conditions was carried out by several researchers [8-11].
Several past contributions on the flow through saturated soil are available, including laboratory investigations [12-16] and field-based studies [17-19].

The current investigation is intended to carry out an in-depth analysis of flow characteristics through saturated soil under variable head condition through laboratory test. Basic concepts on various parameters of soil are emphasized by performing several experiments for better understanding of the complexity of flow characteristics.

\section{Mathematical Correlations}

In this section, the mathematical correlations for linear and nonlinear flow through porous media have been described.

Referring to Fig. 1 where a uniform flow of fluid is taking place through a soil mass of length $L$ and cross-sectional area $A$, under a net head of $h$, the net discharge being $Q$.

After Darcy's law of permeability [20], the following correlation holds good:

$$
Q=k i A
$$

where, $i$ is the hydraulic gradient $(=h / L)$ and $k$ is the hydraulic conductivity. The average flow velocity $(v=Q / A)$ is given by the following correlation:

$$
i={ }_{k}^{\overline{1}} v
$$




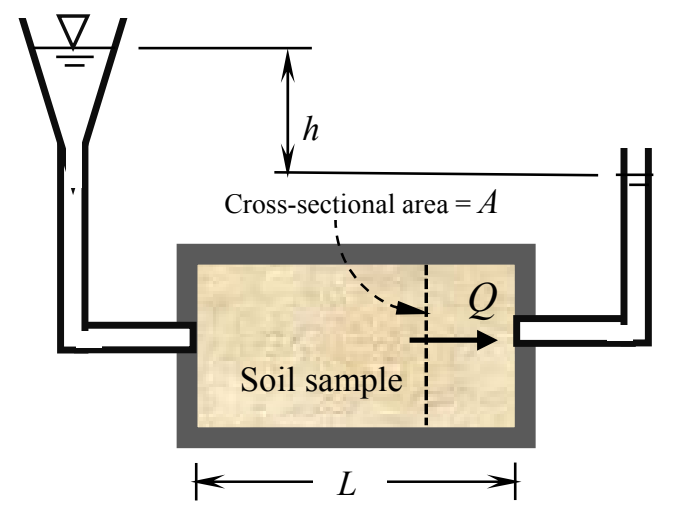

Fig.1. Flow of fluid through saturated soil mass: basic conception

When the net head $h$ is low, the flow in linear, hence Equations (1) and (2) are valid. However, for higher values of $h$, the flow through soil mass becomes nonlinear, and the Forchheimer's Equation [21] holds good, which is given by:

$$
i=\frac{1}{k_{1}} v+\frac{1}{k_{2}} v^{2}
$$

where, $k_{1}$ and $k_{2}$ are termed as the Forchheimer's coefficients, whose values depend upon the soil parameters.

The Eq. (2) above represents a linear correlation between the hydraulic gradient and the average flow velocity, whereas the Eq. (3) implies a parabolic variation of the order of 2 .

The critical velocity is defined as the value of $v$ at which the flow pattern changes from linear to nonlinear or vice versa. Eliminating $I$ from Equations (2) and (3) above, the critical velocity $\left(v_{c r}\right)$ is given by:

$$
v_{c r}=k_{2}\left(\frac{1}{k}-\frac{1}{k_{1}}\right)
$$

Accordingly, the critical hydraulic gradient $\left(i_{c r}\right)$ and the critical head $\left(h_{c r}\right)$ are given by:

$$
h_{c r}=i_{c r} L=\frac{1}{k} v_{c r} L
$$

\section{Experimentation}

The experimentation includes laboratory tests with locally available saturated soft clay bed, to assess the linear and nonlinear flow characteristics.

\subsection{Test Set Up}

The falling head permeameter conforming to standard specifications [22] were used to carry out the tests (see Fig.2).

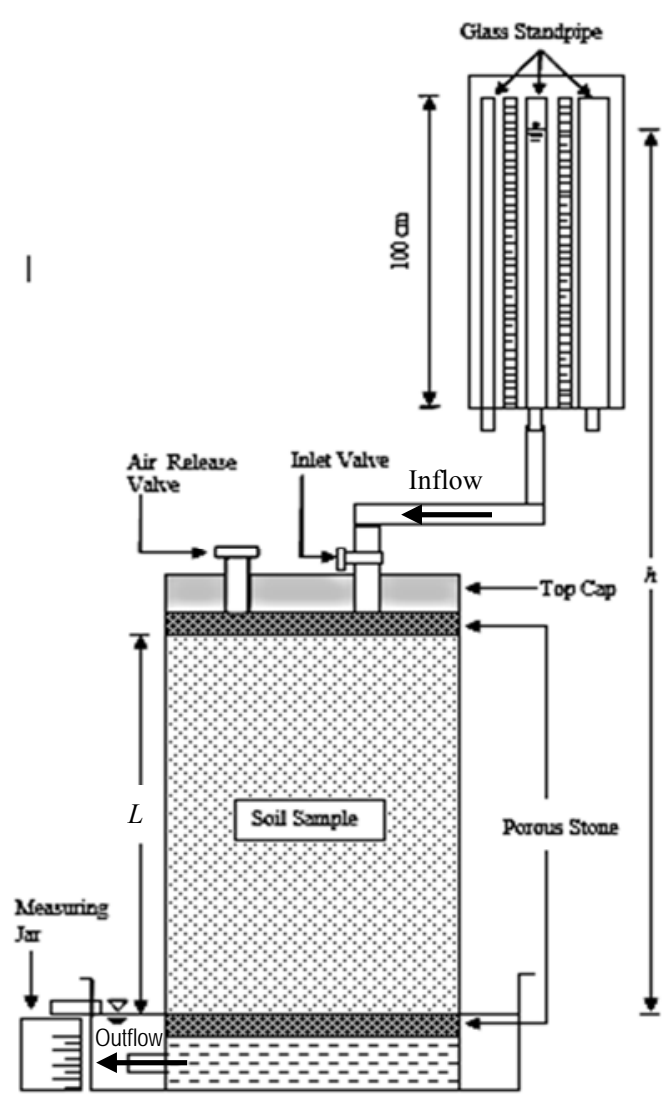

(a)

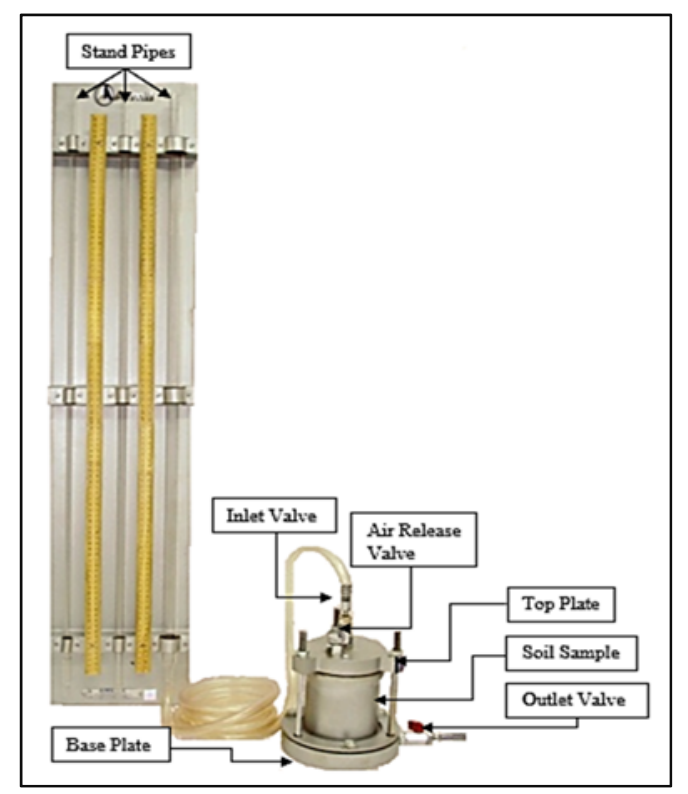

(b)

Fig.2. The falling head permeameter:

(a) schematic diagram, and (b) photographic view

The dimensions of various components of the falling head permeameter are as follows: 

$\mathrm{m}^{2}$

Area of standpipe cross section, $a=314 \times 10^{-6}$

Cross sectional area of mould, $A=127 \times 10^{-4} \mathrm{~m}^{2}$

Length of mould, $L=0.127 \mathrm{~m}$

With ascend of time, the head $h$ gradually reduces. The test involves recording the values of $h$ at selected time instances $t$. The recording is continued till the head diminishes to ensure no flow (i.e., $\mathrm{v}=0$ ). The porous stone at the top and the bottom creates obstruction of suspended and colloidal particles from inflowing water into the soil mass, thereby eliminating any clogging of its void spaces.

\subsection{Soil}

The undisturbed soil sample was collected from a depth of $1 \mathrm{~m}$ in a nearby excavation peat in the campus of Kaziranga University, Assam, India. The natural moisture content of the collected soil mass was $17 \%$. A particle size distribution done indicates a clay content of $32.2 \%$, silt of $25.8 \%$ and fine sand of $42 \%$. The particle size distribution curve is given in Fig.3. The uniformity coefficient and the coefficient of curvature have been evaluated as $C_{u}=20$ and $C_{c}=2.25$. The soil is therefore classified as well graded low plasticity $c-\phi$ soil [23].

The engineering properties of the soil was determined in by standard laboratory tests, as presented in Table I.

Table I: Engineering properties of soil

\begin{tabular}{|l|l|c|}
\hline \multicolumn{2}{|c|}{ Parameter } & Value \\
\hline Specific gravity of solids, $G$ & 2.56 \\
\hline \multirow{4}{*}{ Atterberg Limits } & Liquid limit & $24.8 \%$ \\
\cline { 2 - 3 } & Plastic Limit & $16.5 \%$ \\
\cline { 2 - 3 } & Shrinkage Limit & $6.5 \%$ \\
\hline $\begin{array}{l}\text { Standard Proctor } \\
\text { Compaction Test }\end{array}$ & $\begin{array}{l}\text { Maximum dry } \\
\text { density }\end{array}$ & $16.9 \mathrm{kN} / \mathrm{m}^{3}$ \\
\cline { 2 - 3 } & $\begin{array}{l}\text { Optimum } \\
\text { moisture } \\
\text { content }\end{array}$ & $7.2 \%$ \\
\hline $\begin{array}{l}\text { Shear Strength } \\
\text { (by Direct Shear } \\
\text { Test) }\end{array}$ & \begin{tabular}{l} 
Unit cohesion, $c$ \\
\cline { 2 - 3 }
\end{tabular} & $20 \mathrm{kPa}$ \\
\hline
\end{tabular}

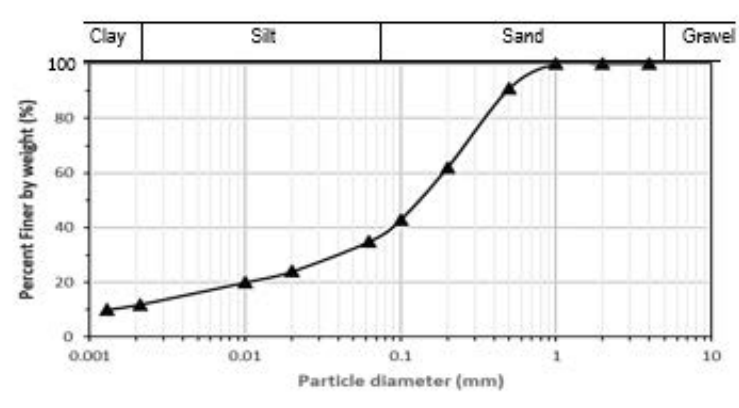

Fig. 3. Particle size distribution curve

\section{Results and Discussions}

The recorded values obtained from the falling head permeameter are presented here and the relevant analyses and interpretations are done.

\subsection{Test Data}

The value of $h$ versus the elapsed time have been plotted by direct use of the observed test data. Three different sets of test were conducted and the average values are shown in Fig.4.

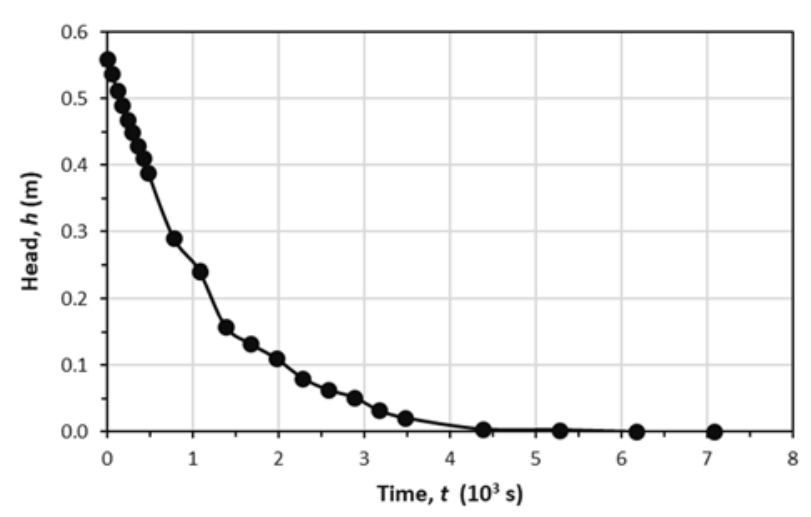

Fig.4. Plot of $h$ versus $t$ from test data

From the above plot, it is observed that parameter $h$ gradually reduced with increasing value of $t$ in a curvilinear manner with ascending slope, and diminished at $t=4500 \mathrm{~s}$.

\subsection{Analysis and Interpretation}

From the above-mentioned test data, the values of hydraulic gradients are computed from the following correlation:

$$
i=\frac{h}{L}
$$

The average flow velocity through the soil mass has been estimated from the test data using the following correlation: 


$$
v_{j}=\left(\frac{d h}{d t}\right)_{j} \approx \frac{h_{j-1}-h_{j+1}}{t_{j+1}-t_{j-1}}
$$

where, $v_{j}$ is the average flow velocity and $h_{j}$ and $t_{j}$ are the values of $h$ and $t$ at $j^{\text {th }}$ instant respectively.

The values of $v$ and $i$ computed above from the observed test data are plotted, as shown in Fig.5. For lower values of hydraulic gradient, the flow is expected to be linear, hence the Eq. (2) is applicable and the best fit line passes through the origin. For higher values of hydraulic gradient, on the other hand, Eq. (3) holds good and the best fit curve is essentially parabolic with ascending slope.

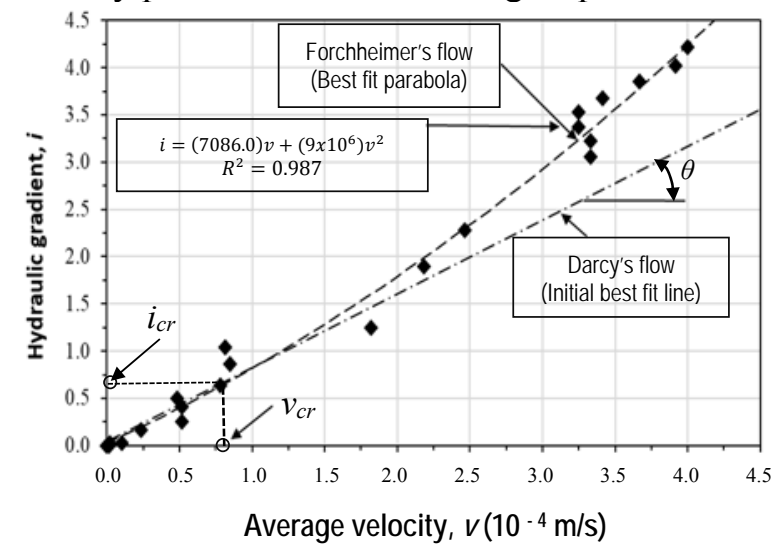

Fig.5. Plot of hydraulic gradient against average flow velocity

From Fig.5 above, the point of intersection between the straight line and the parabola represents the critical point corresponding critical values of velocity and hydraulic gradient. Accordingly, $v_{c r}=0.75 \times 10^{-4} \mathrm{~m} / \mathrm{s}$ and $i_{c r}=0.64$, thus $h_{c r}=0.0813 \mathrm{~m}$.

The value of critical Reynolds number is calculated from the correlation, $R_{e}^{c r}=\rho v_{c r} d_{a v} / \mu$, where, $\rho$ is the mass density of water, $d_{a v}$ is the average particle diameter in $\mathrm{cm}$ and $\mu$ is the kinematic viscosity of water. The average room temperature during experimentation was measured as $21^{\circ} \mathrm{C}$. Thus, $\rho=0.9986 \mathrm{gm} / \mathrm{cm}^{3}$ and $\mu=0.01009 \mathrm{gm} / \mathrm{cm} / \mathrm{s}$ [24]. Also, from Fig.3, $d_{a v}=0.015 \mathrm{~cm}$. Hence, $R_{e}^{c r}=1.11 \times 10^{-2}$.

From Fig.5, the values of $k, k_{1}$ and $k_{2}$ are estimated as follows:

$$
\begin{aligned}
& k=1 / \tan \theta=1.285 \times 10^{-4} \mathrm{~m} / \mathrm{s} \\
& k_{1}=1 / 7086.0=1.411 \times 10^{-4} \mathrm{~m} / \mathrm{s} \\
& k_{2}=1 /\left(9.0 \times 10^{6}\right)=1.111 \times 10^{-7} \mathrm{~m}^{2} / \mathrm{s}^{2}
\end{aligned}
$$

See also [25] and [26].

\section{Conclusion}

The flow characteristics through soil under variable head is quite complex. For lower hydraulic gradient, the flow pattern is linear. On the other hand, the flow pattern for higher hydraulic gradient exhibits nonlinear features. To carry out an in-depth study on the linear and nonlinear flow characteristics, a set of laboratory experimentations have been conducted with locally available saturated soil.

The study reveals that the hydraulic gradient gradually reduced following a curvilinear pattern with increasing time with ascending slope, and diminished at $4500 \mathrm{~s}$.

At lower hydraulic gradients, a linear correlation between the parameters $i$ and $v$ were observed, which implies a Darcy's flow. For higher values of hydraulic gradients, a parabolic correlation of the order of 2 was noted, conforming to Forchheimer's flow. The value of critical Reynolds Number was evaluated as $1.11 \times 10^{-2}$.

\section{Acknowledgements}

The authors acknowledge the infrastructure support received from the Department of Civil Engineering, Kaziranga University, Jorhat, Assam, India, during execution of the investigation. The assistance received from Mr. Rupantor Senapoty, Laboratory Staff of Kaziranga University is also acknowledged. The manuscript is drafted with the infrastructure support from Elitte College of Engineering, Sodepur, Kolkata, India.

\section{Notations:}

$A=$ cross secional area of sample

$a=$ cross sectional area of mould

$C_{c}=$ Coefficient of curvature

$C_{u}=$ Uniformity coefficient

$d_{a v}=$ average particle diameter in $\mathrm{cm}$

$h=$ net head

$h_{c r}=$ critical head

$h_{j}=$ value of $h$ at $j^{\text {th }}$ instant

$i=$ hydraulic gradiant

$i_{c r}=$ critical hydraulic gradiant

$k=$ hydraulic conductivity

$k_{1}, k_{2}=$ Forchheimer's coefficients

$L=$ length of soil mass

$Q=$ net discharge

$t=$ time interval.

$t_{j}=$ value of $t$ at $j^{\text {th }}$ instant

$v=$ average flow velocity

$v_{c r}=$ Critical velocity. 
$V_{j}=$ average flow velocity

$\mu=$ kinematic viscosity of water

$\rho=$ mass density of water

\section{References:}

[1] Basack, S., Bhattacharya, A.K., and Maity., P., A coastal groundwater management model with Indian case study, Proceedings of the Institution of Civil Engineers: Water Management, Vol. 167, No. 3, 2014, pp. 126140.

[2] Bhattacharya A.K., Basack S. and Patra M.N., Land subsidence in Calcutta under the effect of hydrogeological conditions and overextraction of groundwater, Electronic Journal of Geotechnical Engineering, Vol. 9(E), 1-12.

[3] Arora, K. R. Soil mechanics and foundation engineering, Standard Publishers, India, 2011.

[4] Basack, S. and Nimbalkar, S., Free strain analysis of the performance of vertical drains for soft soil improvement, Geomechanics and Engineering, Vol.13, No.6, pp.963-975.

[5] Wang, L., Li, Y., Zhao, G., Chen. N. and Xu, Y., Experimental investigations of flow characteristics in porous media at low Reynold's number under different constant hydraulic heads, Water, Vol. 11, No. 2317, pp. 1-14.

[6] Zhang, R., Ning, Z., Yang, F. and Wang, Q., A laboratory study of the porositypermeability relationships of shale and sandstone under effective stress, International Journal of Rock Mechanics and Mining Sciences, Vol. 81, 2016, pp. 19-27.

[7] Tan, X., Konietzky, H. and Frủhwirt, T. Laboratory observations and numerical simulation of permeability evolution during progressive failure of brittle rocks, International Journal of Rock Mechanics and Mining Sciences, Vol. 68, 2014, pp. 167-176.

[8] Greenly, B. T. and Joy, D. M., Onedimensional finite element model for high flow velocities in porous media, Journal of Geotechnical Engineering, Vol. 122, No. 10, 1996, pp. 789-796.

[9] Lee, S. L. and Yang, J. H., Modelling of Darcy-Forchheimer drag for fluid flow across a bank of circular cylinders, International Journal of Heat and Mass Transfer, Vol. 40, 1997, pp. 3149-3155.

[10] Panfilov, M. and Fourar, M., Physical splitting of nonlinear effects in high velocity stable flow through porous media, Advances in Water Resources, Vol. 29, No.1, 2006, pp. 30-41.

[11] Wan, J., Huang, K. and Chen, C. X., Reassessing Darcy's law on water in porous media, Earth Science Journal, Vol. 38, 2013, pp. 1327-1330.

[12] Olsen, H. W., Hydraulic Flow through Saturated Clays, in Proc. $9^{\text {th }}$ National Conference on Clays and Clay Minerals, 1960, pp. $131-161$.

[13] Chapuis, R. P., Predicting the saturated hydraulic conductivity of sand and gravel using effective diameter and void ratio, Canadian Geotechnical Journal, Vol. 41, 2004, pp. 787-795.

[14] Singh, P. N. and Wesley, W. Effects of Adsorbed Water Layer in Predicting Saturated Hydraulic Conductivity for Clays with Kozeny-Carman Equation, Journal of Geotechnical and Geoenvironmental Engineering, Vol. 134, No. 6, 2008, pp. 829836.

[15] Tang, L. S., Chen, H. and Song, J., Process of pore pressure diffusion in saturated clay soil and impact of adsorbed water, Geosciences Journal, Vol. 20, 2016, pp. 649-665.

[16] Dafalla, M. and Obaid, A., Assessment of Flow Through Clay-sand Liners using Laboratory Models, KSCA Journal of Civil Engineering, Vol. 22, 2018, pp. 1684-1690.

[17] Bouma, J., Field measurement of soil hydraulic properties characterizing water movement through swelling clay soils, Journal of Hydrology, Vol. 45, Issue 1-2, 1980, pp. 149158.

[18] Saadeldin, R. and Henni, A., A novel modeling approach for the simulation of soil-water interaction in a highly plastic clay, Geomechanics and Geophysics for Geo-Energy and Geo-Resources, Vol.2, 2016, pp. 77-95.

[19] Cheng, C. and Chen, X., Evaluation of methods for determination of hydraulic properties in an aquifer-aquitard system hydrologically connected to a river, Hydrogeology Journal, Vol. 15, 2007, pp. 669-678.

[20] Darcy, H., Publiquis de la Ville de Dijon, Librainie des Corps Imperiaux des Ponts et Chaussess et des Mines, Paris, 1856.

[21] Forchheimer, P., Wasserbewegung durch boden, Z. Ver. Dtsch. Ing., Vol. 45, 1901, pp. 1782-1788.

[22] ASTM D5084-03, Standard Test Methods for Measurement of Hydraulic Conductivity of 
Saturated Porous Materials Using a Flexible Wall Permeameter, ASTM International, West Conshohocken, PA, 2003.

[23] USDD, Unified soil classification System for Roads, Airfields, Embankments and Foundations. Military Standard; MIL - STD 619 A, U.S. Department of Defense, Washington 25, D.C. 1962.

[24] Zhang, Z. S. and Cui, G. X., Fluid Dynamics, $3^{\text {rd }}$ Edition, Tsinghua University Press, Beijing, China, 2015.

[25] Ekaterina Rouvinskaya, Oxana Kurkina, Andrey Kurkin, Andrey Zaytsev, Modeling of Internal Wave Impact on Hypothetical Pillars of Hydraulic Engineering Constructions in the Conditions of the Sakhalin Island Shelf, WSEAS Transactions on Fluid Mechanics, Volume 13, 2018, pp. 101-107

[26] K. Kotrasova and E. Kormanikova, Frequency analysis of partially-filled rectangular water tank, International Journal of Mechanics, pp.59-66, Volume 12, 2018 